\title{
Desempenho de Espécies Florestais e Pastagens em Sistemas Silvipastoris no Estado do Pará
}

\author{
Célia Maria Braga Calandrini de Azevedo(1), Jonas Bastos da Veiga(2), Jorge Alberto Gazel Yared ${ }^{(3)}$ e Luciano \\ Carlos Tavares Marques ${ }^{(1)}$
}

\begin{abstract}
(1)Embrapa Amazônia Oriental, Tv. Dr. Enéas Pinheiro s/n., CEP 66095-100, Belém-PA. E-mails: celiambs@cpatu.embrapa.br; luciano@cpatu.embrapa.br; (2)Instituto de Desenvolvimento Econômico, Social e Ambiental do Pará (Idesp), Rua Municipalidade 146, CEP 66050-350, Belém-PA. E-mail: jonas.veiga@idesp.pa.gov.br; (3)Ideflor, Rua Boaventura da Silva, 159, CEP 66060-060, Belém-PA. E-mail: jagyared@gmail.com
\end{abstract}

Resumo - Propor modelos alternativos de uso-da-terra que sejam econômicos e ecologicamente sustentáveis tem sido um grande desafio da pesquisa agrícola na Amazônia. Os sistemas silvipastoris (SSPs) têm sido considerados promissores para integrar o cultivo arbóreo nos sistemas pecuários e recuperar pastagens degradadas da Amazônia. Em Paragominas, Estado do Pará, foram estudados nove sistemas silvipastoris constituídos da combinação binária das espécies florestais paricá (Schizolobium amazonicum), tatajuba (Bagassa guianensis) e eucalipto (Eucalyptus tereticornis), plantadas em faixas de $6 \mathrm{~m}$ de largura, afastadas de $12 \mathrm{~m}$, com as pastagens capim braquiarão (Brachiaria brizantha), capim quicuio da amazônia (B. humidicola), e capim colonião (Panicum maximum) e em capim dictioneura ( $B$. dictyoneura), plantadas nas entre-faixas. O sistema de manejo se caracterizava por ser rotacionado com 14 dias de permanência e 42 dias de descanso, e foi avaliado no período de agosto de 1990 a novembro de 1991. As melhores interações foram paricá e capim braquiarão e eucalipto e capim braquiarão.

Termos para indexação: Integração árvore-pastagem, crescimento de árvores, produção de pastagem, capacidade de suporte, Amazônia brasileira.

\section{Performance of Tree Species and Pastures in Silvopastoral Systems in the State of Pará, Brazil}

\begin{abstract}
Proposing economic and ecological land-use alternatives has been a great challenge for agricultural research in the Brazilian Amazon. The silvopastoral systems (SPS) are promising to integrate trees in the livestock production system and reclaim degraded pastures in the Amazon region. In Municipality of Paragominas, State of Pará, nine SPS composed by combination of three tree species (Schizolobium amazonicum, Bagassa guianensis and Eucalyptus tereticornis), planted in $6 \mathrm{~m}$-lane, spaced by $12 \mathrm{~m}$ - and three pastures (Brachiaria brizantha, B. humidicola and Panicum maximum / dictioneura B. dictyoneura), planted in the inter-lane space. Steers grazed the one-hectare experimental parcels simulating a rotational grazing system with 14 days - grazing period and 42 days - rest period, and was evaluated during August 1990 to November 1991. From the tree and pasture management point of view, the more promising silvopastoral combinations were, respectively, S. amazonicum - B. brizantha and E. tereticornis - B. brizantha.
\end{abstract}

Index terms: Tree-pasture integration, tree development, pasture production, carry capacity, Brazilian Amazon.

\section{Introdução}

A Amazônia Brasileira possui 330 milhões de hectares, dos quais, atualmente, cerca de 70 milhões estão desmatados e cuja metade está abandonada. Os principais agentes de desmatamento na região são a pecuária, exploração de madeira e produtos nãomadeireiros, agricultura de corte e queima e, mais recentemente, a agricultura mecanizada de grãos (ALMEIDA et al., 2006).
Os sistemas silvipastoris (SSPs) e agrossilvipastoris (SASPs), que integram lavoura, pecuária e silvicultura, têm despertado interesse na comunidade cientifica, na busca de novas alternativas de exploração da terra que seja biológica, econômica e ecologicamente mais sustentável que os sistemas convencionais (VEIGA; TOURRAND, 2002).

Entre as vantagens desses sistemas, destacam-se a sombra para os animais, o melhoramento do solo, o controle da erosão, o melhoramento das condições 
microclimáticas, a diversificação da produção e dos serviços, o aumento da produtividade por hectare, a amortização dos custos de plantio e manutenção florestal, e a melhor composição da paisagem (VEIGA; TOURRAND, 2002).

Vários estudos têm sido desenvolvidos na região amazônica para avaliar o desempenho de árvores e arbustos para uso em SSP ou SASP (BRIENZA JÚNIOR; YARED, 1991; FRANKE, 1999; MANESCHY, 2008; MOCHIUTTI; MEIRELLES, 2001; VEIGA; MARQUES, 1998). Entre as espécies estudadas, destacam-se o paricá, a tatajuba e o eucalipto.

Em SSP, a performance da pastagem depende da densidade das árvores e da sua altura, arquitetura e fenologia (VEIGA et al., 2001). Carvalho et al. (1998) verificaram uma drástica redução $(56 \%)$ da produção de forragem do capim braquiarão quando estabelecido no sub-bosque de angico-vermelho (Anadenanthera macrocarpa), sob 40\% de luz. Ademais, a sombra pode reduzir a proporção do tecido mais digestível da folha (o mesófilo) e aumentar a do menos digestível (a epiderme) (GARCIA; COUTO, 1997), enquanto a proteína bruta de gramíneas pode diminuir com o sombreamento (COSTA et al., 2006) ou, segundo Costa et al. (2006) pode diminuir com o sombreamento ou, segundo Castro et al. (1998), aumentar.

Este trabalho objetivou avaliar, em Paragominas, Pará, o desempenho de espécies florestais e forrageiras em SSPs compostos pela associação de paricá (Schizolobium amazonicum), tatajuba (Bagassa guianensis) e eucalipto (Eucalyptus tereticornis) com o capim braquiarão (Brachiaria brizantha), capim quicuio da amazônia ( $B$. humidicola) e capim colonião (Panicum maximum), depois substiuído pela dictioneura (B. dictyoneura).

\section{Material e Métodos}

\section{Características da área}

O experimento foi conduzido em uma área de capoeira no Campo Experimental da Embrapa, no Município de Paragominas, Estado do Pará, a $03^{\circ} 05^{\prime}$ lat. Sul e $47^{\circ} 21^{\prime}$ lat. Oeste, no período de janeiro de 1985 a janeiro de 1992.

O solo é do tipo Latossolo Amarelo de textura muito argilosa. O clima $\mathrm{Aw}_{\mathrm{i}}$, segundo classificação de Köppen, com temperatura média anual de $26,9^{\circ} \mathrm{C}$ e precipitação média anual de $1.864 \mathrm{~mm}$. A época seca vai de junho a novembro. Aspectos da análise granulométrica e fertilidade do solo: areia (g. $\left.\mathrm{kg}^{-1}\right)$ 30; silte $\left(\mathrm{g} . \mathrm{kg}^{-1}\right)$ 340; argila $\left({\left.\mathrm{g} . \mathrm{kg}^{-1}\right)}^{-1} 630 ; \mathrm{pH}\left(\mathrm{H}_{2} \mathrm{O}\right)\right.$ 5,9; $\mathrm{MO}\left(\right.$ g.kg $\left.{ }^{-1}\right) 27 ; \mathrm{P}$ $\left(\mathrm{MG} \cdot \mathrm{dm}^{-3}\right)$ 1,0; $\mathrm{Ca}\left(\mathrm{cmol}_{\mathrm{c}} \cdot \mathrm{dm}^{-3}\right) 4,4 ; \mathrm{Mg}\left(\mathrm{cmol}_{\mathrm{c}} \cdot \mathrm{dm}^{-3}\right)$ $0,1 \mathrm{e} \mathrm{Al}\left(\mathrm{cmol}_{\mathrm{c}} \cdot \mathrm{dm}^{-3}\right)$ 0,0 na, profundidade de 0 a $20 \mathrm{~cm}$.

\section{Delineamento experimental e tratamentos}

Num delineamento de blocos ao acaso, sem repetição, foram comparados os SSPs compostos pela combinação de cada uma das espécies florestais, paricá (Schizolobium amazonicum Huber ex Ducke), tatajuba (Bagassa guianensis Aubl) e eucalipto (Eucalyptus tereticornis Smith), com cada uma das gramíneas forrageiras, capim braquiarão (Brachiaria brizantha (Hochst. ex A. Rich) Stapf), capim quicuio da amazônia ( $B$. humidicola (Rendle) Schweick) e capim colonião (Panicum maximum Jacq.) (substituído posteriormente pelo capim dictioneura (B. dictyoneura Fig. \& De Not.) Stapf), formando ao todo nove SSPs, com um hectare cada (Figura 1). 


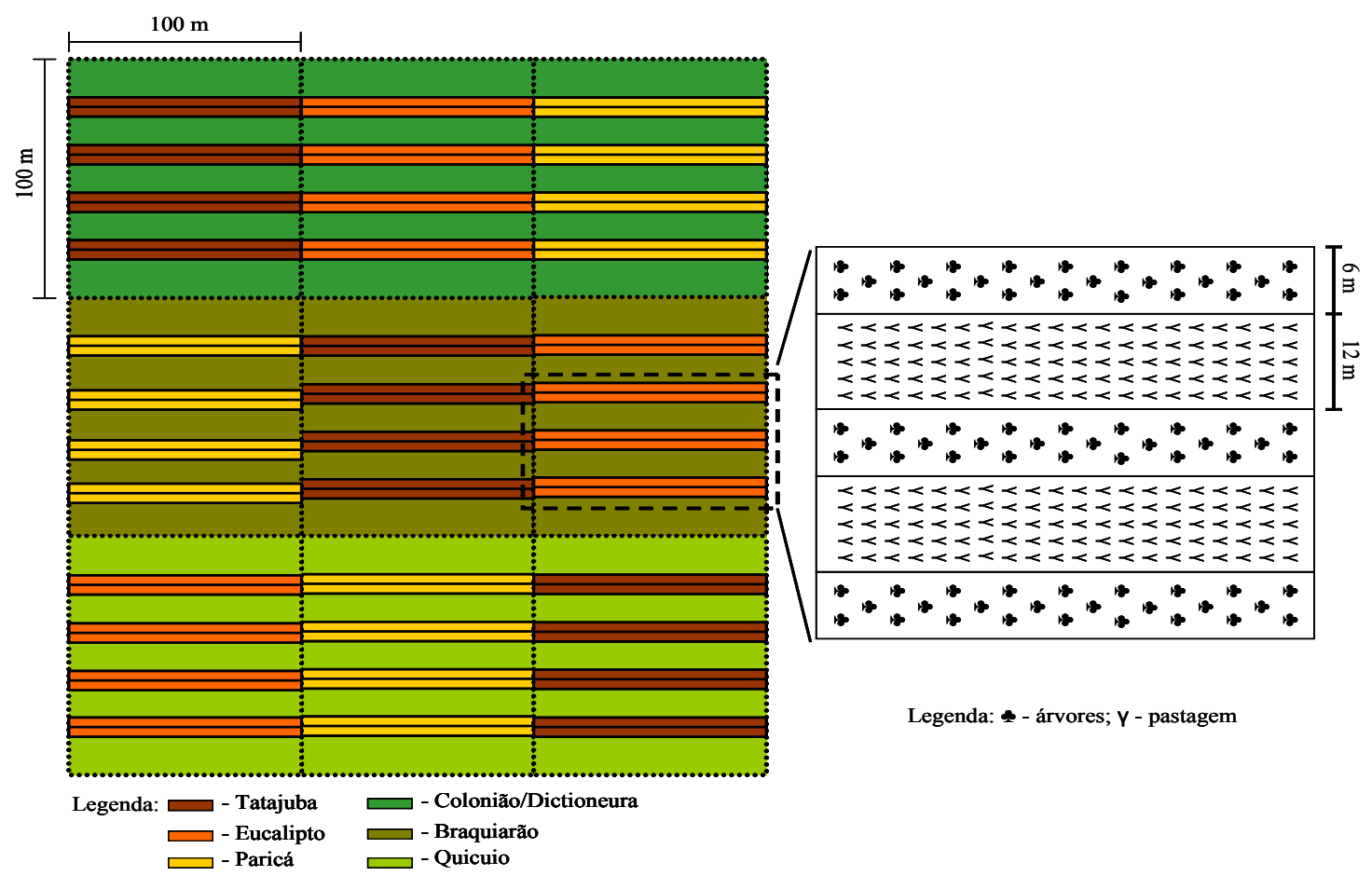

Figura 1. Desenho do ensaio silvipastoril em Paragominas, Pará.

\section{Estabelecimento dos sistemas silvipastoris}

Depois da vegetação ter sido roçada e queimada, e o solo gradeado, mudas das árvores foram plantadas em faixas espaçadas de $12 \mathrm{~m}$. Nas faixas, constituídas de três linhas de plantio, o espaçamento foi de $3 \mathrm{~m} \mathrm{x} 3$ $\mathrm{m}$, em arranjo quinconcial, resultando numa densidade de 555 árvores por ha (Figura 1). A adubação foi de $50 \mathrm{~g}$ e $150 \mathrm{~g}$ da fórmula $\mathrm{N}, \mathrm{P}_{2} \mathrm{O}_{5}, \mathrm{~K}_{2} \mathrm{O}$ (15-25-12) por planta, no plantio e após 60 dias, respectivamente. Num espaçamento de $1 \mathrm{~m} \mathrm{x} 1 \mathrm{~m}$, o milho (cv. BR-5102) foi plantado entre as linhas e as faixas das árvores, no primeiro ano, e somente entre as faixas, no segundo, adubado com $205 \mathrm{~kg} \cdot \mathrm{ha}^{-1}$ da fórmula $\mathrm{N}, \mathrm{P}_{2} \mathrm{O}_{5}, \mathrm{~K}_{2} \mathrm{O} 20-29-15$. Um quarto do nitrogênio, na forma de uréia, foi aplicado no plantio, e o restante, em cobertura, 40 dias depois. No terceiro ano e entre as faixas das árvores, as pastagens de capim braquiarão, capim quicuio da amazônia e capim colonião foram semeadas em associação com milho, aplicando-se $130 \mathrm{~kg} \cdot \mathrm{ha}^{-1}$ da fórmula $\mathrm{N}, \mathrm{P}_{2} \mathrm{O}_{5}, \mathrm{~K}_{2} \mathrm{O}$ (40-60-30).

\section{Manejo da pastagem}

Quatorze meses após o plantio das pastagens e 40 meses do plantio das árvores, teve início o pastejo regular dos SSPs com capim braquiarão e capim colonião. Por demora no estabelecimento, o pastejo dos SSPs com capim quicuio da amazônia só foi iniciado 19 meses depois. Por problemas de persistência, a pastagem de capim colonião foi avaliada por apenas 5 meses, sendo substituída 21 meses depois pela de capim dictioneura. A demora no início do pastejo ocorreu devido a problemas no estabelecimento das forrageiras ocasionados por período atípico de intensa seca na região.

A utilização da pastagem de cada SSP era feita periodicamente por novilhos nelorados de 200-250 $\mathrm{kg}$, simulando um sistema rotacionado com 14 dias de pastejo e 42 dias de descanso. A lotação animal era variável para permitir as seguintes alturas de resíduo da pastagem: braquiarão $35-45 \mathrm{~cm}$, quicuio $15-25 \mathrm{~cm}$, colonião $50-65 \mathrm{~cm}$ e dictioneura $20-30 \mathrm{~cm}$.

\section{Avaliação dos componentes dos sistemas silvipastoris}

\section{Espécies florestais}

As espécies florestais foram avaliadas até aos 84 meses, três meses após um fogo acidental que impediu a continuação do estudo. $\mathrm{O}$ efeito das pastagens nas espécies florestais foi medido na avaliação de 42 meses.

O crescimento de 100 árvores de cada SSP foi medido a cada seis meses, até os 48 meses, e a cada 12 meses, até os 84 meses. Nos primeiros 12 meses, a altura foi medida com régua graduada e após com aparelho "blumelaiss". Para avaliar o DAP, utilizaram-se um paquímetro e uma fita diamétrica. 


\section{Pastagens}

A avaliação das pastagens em SSP foi feita com base no capim braquiarão, capim quicuio da amazônia e capim dictioneura, em pastejos efetuados de agosto de 1990 a novembro de 1991.

Em cada SSP, a massa de forragem foi avaliada a cada 56 dias, antes da entrada dos animais, em cinco áreas de $1 \mathrm{~m}^{2}$, ao acaso, cortando-se o capim braquiarão, o capim dictioneura e o cpim quicuio da amazônia a $10 \mathrm{~cm}, 5 \mathrm{~cm}$ e $5 \mathrm{~cm}$ do solo, respectivamente. A proteína bruta (PB) da folha foi determinada em amostras compostas, pelo método de Kjeldahl (ASSOCIATION OF OFFICIAL ANALYTICAL CHEMISTS, 1970).

\section{Análise dos dados}

Os dados foram tratados pelo software NTIA, desenvolvido pela Embrapa Informática para Agropecuária, Campinas, versão 4.2.1 de outubro de 1995. Nas análises de variância, utilizou-se o método dos mínimos quadrados. A significância dos fatores estudados foi feita pelo teste $\mathrm{F}$ e as médias foram comparadas pelo teste Tukey ao nível de 5\% de probabilidade.

\section{Resultados e Discussão}

\section{Desempenho das espécies florestais}

\section{Altura e diâmetro à altura do peito (DAP)}

Em todas as espécies florestais, houve uma relação linear positiva entre a altura e a idade, com elevados coeficientes de determinação $\left(\mathrm{R}^{2}\right)$, mostrando um grande ajuste das equações (Figura 2). Já a relação do DAP com a idade foi exponencial no paricá e tatajuba, e linear no eucalipto, também com elevados coeficientes de determinação (Figura 3).

As taxas de crescimento do eucalipto em DAP se mantiveram constantes ao longo do tempo, enquanto as das outras espécies tenderam a crescer. Analisando as curvas da altura e do DAP, não foi possível ter uma idéia do potencial produtivo máximo das espécies florestais no período estudado (84 meses).

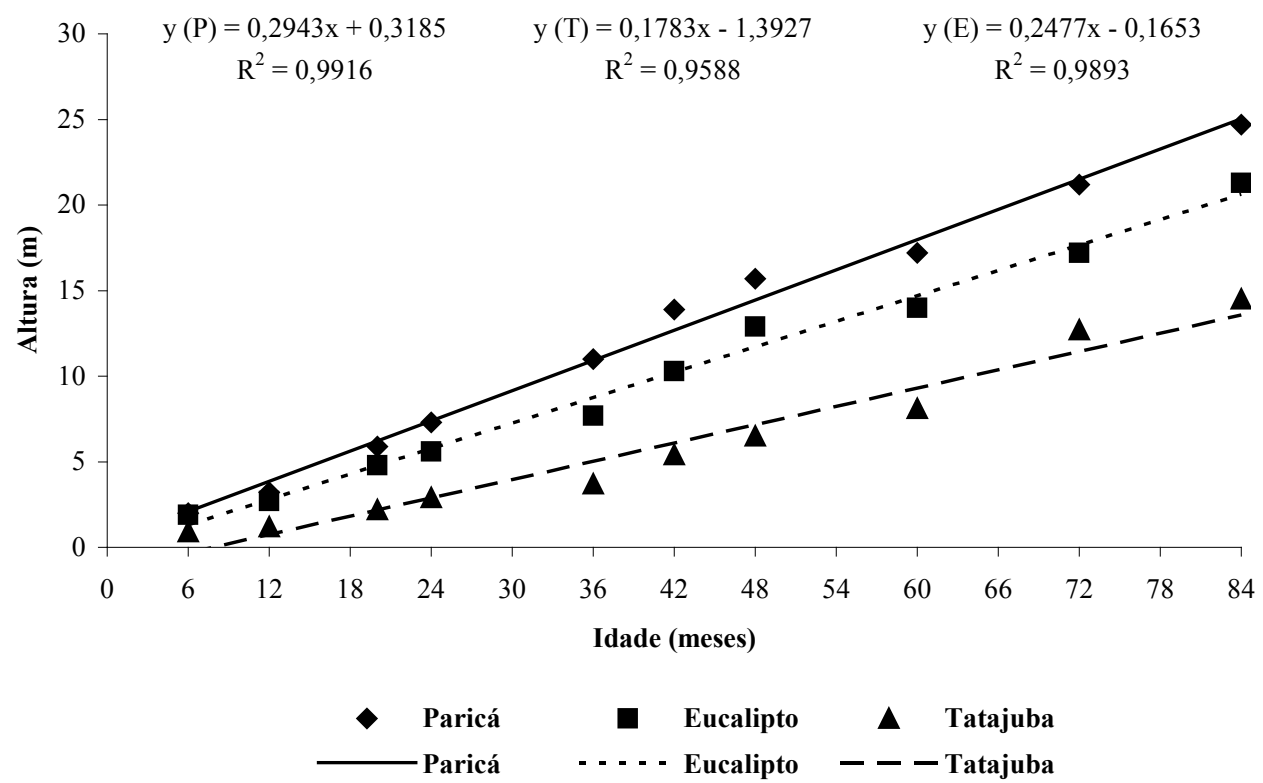

Figura 2. Relação entre altura e idade das espécies florestais estudadas em sistemas silvipastoris em Paragominas, Pará. 


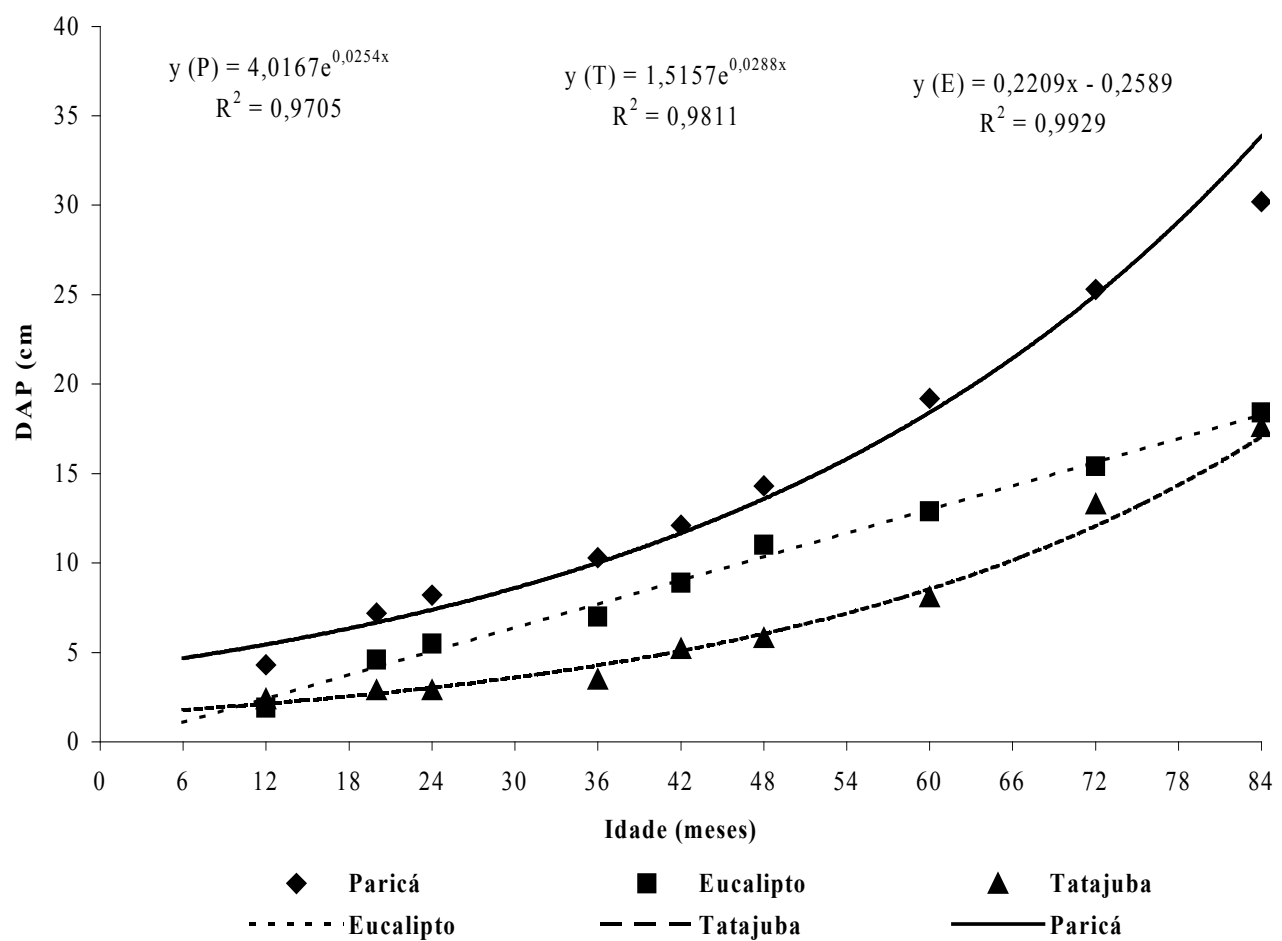

Figura 3. Relação entre DAP e idade das espécies florestais estudadas em sistemas silvipastoris em Paragominas, Pará.

O paricá apresentou o melhor desenvolvimento em altura e DAP, seguido do eucalipto e da tatajuba. As diferenças em altura aumentaram com a idade, enquanto as diferenças em DAP só aumentaram entre o paricá e eucalipto, e a tatajuba tendeu a se igualar ao eucalipto. A baixa performance da tatajuba em quase todo período ocorreu provavelmente pelo consumo dos brotos das plantas jovens por animais silvestres (MARQUES, 1990).

Aos 84 meses, a altura e o DAP médios do paricá, eucalipto e tatajuba foram $24,7 \mathrm{~m}$ e $30,2 \mathrm{~cm} ; 21,3 \mathrm{~m}$ e $18,4 \mathrm{~cm}$; e $14,5 \mathrm{~m}$ e $17,6 \mathrm{~cm}$, respectivamente.

Na região amazônica, ainda são poucos os trabalhos publicados sobre o crescimento de espécies florestais em SSP, além da fase de estabelecimento. Em Roraima, dentre várias espécies, foram destacados o desempenho em altura e DAP do paricá, tatajuba e eucalipto (FERREIRA et al., 2005) e do paricá e eucalipto (Eucalyptus urograndis) (ARCO-VERDE; SCHWENGBER, 2003), em sistemas agroflorestais.

O paricá, pelo seu rápido crescimento, tem sido uma das espécies mais estudadas na região. Aos 36 meses de idade, os valores de altura $(11,0 \mathrm{~m})$ e DAP $(10,3$ $\mathrm{cm}$ ) foram semelhantes àqueles reportados por Ribeiro
(1997) (altura de 13,16 m e DAP de 13,76 cm), aos 32 meses, em sistemas agroflorestais.

\section{Sobrevivência}

Até aos 72 meses, a sobrevivência do paricá e do eucalipto foi acima de $94 \%$, sendo considerada muito boa (Tabela 1). A excelente sobrevivência do paricá em SAF tem sido documentada na literatura (RIBEIRO, 1997).

Tabela 1. Sobrevivência das espécies florestais em sistemas silvipastoris Paragominas, Pará.

\begin{tabular}{cccc}
\hline \multirow{2}{*}{$\begin{array}{c}\text { Idade } \\
\text { (meses) }\end{array}$} & \multicolumn{3}{c}{ Sobrevivência (\%) } \\
\cline { 2 - 4 } & Paricá & Tatajuba & Eucalipto \\
\hline 6 & 99 & 92 & 96 \\
12 & 99 & 92 & 95 \\
20 & 99 & 92 & 95 \\
24 & 99 & 88 & 95 \\
36 & 99 & 88 & 95 \\
42 & 99 & 88 & 95 \\
48 & 99 & 88 & 95 \\
60 & 99 & 88 & 95 \\
72 & 99 & 88 & 95 \\
\hline
\end{tabular}


A queda da sobrevivência da tatajuba entre 20 e 24 meses pode ser atribuída a danos causados por animais silvestres (MARQUES, 1990).

\section{Efeito das pastagens no desempenho das espécies florestais}

A interação espécie florestal x pastagens foi significativa $(\mathrm{P} \leq 0,01)$ apenas na altura e volume. Todas as espécies florestais apresentaram melhor desempenho em associação com o capim braquiarão do que o capim colonião e capim quicuio da amazônia (Tabela 2).

Tabela 2. Altura (m), DAP $(\mathrm{cm})$ e volume $\left(\mathrm{m}^{3}\right)$ de espécies florestais associadas às pastagens de capim braquiarão, capim quicuio da Amazônia e capim colonião, em Paragominas, Pará.

\begin{tabular}{|c|c|c|c|c|}
\hline \multirow[b]{2}{*}{ Pastagens } & \multicolumn{4}{|c|}{ Altura (m) } \\
\hline & Paricá & Eucalipto & Tatajuba & $\begin{array}{c}\text { Média } \\
\text { geral }\end{array}$ \\
\hline Braquiarão & $15,88 \mathrm{aA}$ & $10,73 \mathrm{aB}$ & $5,85 \mathrm{aC}$ & 10,82 \\
\hline Quicuio & $14,05 \mathrm{bA}$ & $10,55 \mathrm{abB}$ & $5,78 \mathrm{aC}$ & 10,13 \\
\hline Colonião & $11,77 \mathrm{cA}$ & $9,77 \mathrm{bB}$ & $4,48 b \mathrm{~b}$ & 8,67 \\
\hline \multirow[t]{3}{*}{$\begin{array}{l}\text { Média } \\
\text { geral }\end{array}$} & 13,90 & 10,35 & 5,37 & - \\
\hline & \multicolumn{4}{|c|}{ DAP (cm) } \\
\hline & Paricá & Eucalipto & Tatajuba & $\begin{array}{c}\text { Média } \\
\text { geral }\end{array}$ \\
\hline Braquiarão & $4,00 \mathrm{aA}$ & $3,13 \mathrm{aB}$ & $1,77 \mathrm{aC}$ & 2,97 \\
\hline Quicuio & $4,09 \mathrm{aA}$ & $2,87 \mathrm{bB}$ & $1,82 \mathrm{aC}$ & 2,93 \\
\hline Colonião & $3,41 \mathrm{bA}$ & $2,58 \mathrm{cB}$ & $1,27 \mathrm{bC}$ & 2,42 \\
\hline \multirow[t]{3}{*}{$\begin{array}{l}\text { Média } \\
\text { geral }\end{array}$} & 3,83 & 2,86 & 1,62 & - \\
\hline & \multicolumn{4}{|c|}{ Volume $\left(\mathrm{m}^{3}\right)$} \\
\hline & Paricá & Eucalipto & Tatajuba & $\begin{array}{c}\text { Média } \\
\text { geral }\end{array}$ \\
\hline Braquiarão & $0,0213 \mathrm{aA}$ & $0,0095 \mathrm{aB}$ & $0,0019 \mathrm{aC}$ & 0,0109 \\
\hline Quicuio & $0,0195 \mathrm{aA}$ & $0,0075 \mathrm{abB}$ & $0,0017 \mathrm{aC}$ & 0,0096 \\
\hline Colonião & $0,0119 \mathrm{bA}$ & $0,0059 \mathrm{bB}$ & $0,0006 \mathrm{aC}$ & 0,0061 \\
\hline $\begin{array}{l}\text { Média } \\
\text { geral }\end{array}$ & 0,0176 & 0,0076 & 0,0014 & - \\
\hline
\end{tabular}

Médias seguidas da mesma letra (minúscula na coluna e maiúscula na linha) não diferem entre si $(\mathrm{P}>0,05)$ pelo teste de Tukey.

Esses dados também revelam a superioridade do paricá em qualquer combinação silvipastoril estudada. Alguns autores têm destacado o desempenho desta espécie em sistemas agroflorestais (RIBEIRO, 1997; FERREIRA et al., 2005). Comparativamente ao capim quicuio da amazônia, o capim braquiarão tem hábito de crescimento mais ereto e menos agressivo, o que pode justificar a sua menor competitividade com as árvores associadas. Por outro lado, o efeito negativo do colonião no crescimento das árvores pode ser atribuído à sua maior exigência em nutrientes do solo.

\section{Desempenho das pastagens}

\section{Massa de forragem}

Houve efeito significativo $(\mathrm{P} \leq 0,01)$ da interação espécie florestais $\mathrm{x}$ pastagens na massa de forragem do capim braquiarão, capim quicuio da amazônia e capim dictioneura. $\mathrm{O}$ capim braquiarão apresentou maior massa de forragem em todas as combinações silvipastoris. De modo geral, as pastagens no sub-bosque da tatajuba e do eucalipto apresentaram maior massa de forragem (Tabela 3). Em Rondônia, Costa et al . (2001) também observaram uma boa produção forrageira do capim braquiarão em sistemas silvipastoris com o eucalipto.

Tabela 3. Massa de forragem total (t MS.ha $\left.{ }^{-1}\right)$ do capim braquiarão, capim quicuio da amazônia e capim dictioneura em sistemas silvipastoris com paricá, tatajuba e eucalipto em Paragominas, Pará.

\begin{tabular}{lcccc}
\hline \multirow{2}{*}{ Pastagens } & \multicolumn{3}{c}{ Espécies florestais } & Média \\
\cline { 2 - 3 } & Paricá & Tatajuba & \multicolumn{1}{c}{ Eucalipto } & geral \\
\hline Braquiarão & $5,6 \mathrm{aB}$ & $6,2 \mathrm{aAB}$ & $6,2 \mathrm{aA}$ & $\mathbf{6 , 0 a}$ \\
Quicuio & $1,6 \mathrm{cB}$ & $3,7 \mathrm{bA}$ & $3,5 \mathrm{cA}$ & $\mathbf{2 , 9 c}$ \\
Dictioneura & $3,5 \mathrm{bB}$ & $4,1 \mathrm{bAB}$ & $4,1 \mathrm{bA}$ & $\mathbf{3 , 9 b}$ \\
\hline Média geral & $\mathbf{3 , 6 B}$ & $\mathbf{4 , 6 A}$ & $\mathbf{4 , 6 A}$ & - \\
\hline
\end{tabular}

Médias seguidas da mesma letra (minúscula na coluna e maiúscula na linha) não diferem entre si $(\mathrm{P}>0,05)$ pelo teste de Tukey.

Embora a disponibilidade de luz não tenha sido medida no presente estudo, a menor massa de forragem sob o paricá possivelmente ocorreu pela menor incidência de luz no sub-bosque dessa espécie, causada pelo seu maior crescimento. Diversos estudos têm mostrado grande variabilidade no comportamento de espécies forrageiras tropicais em função do nível de sombreamento (CARVALHO et al., 1998; COSTA et al., 2001; PORFÍRIO-DA-SILVA, 2001; 2007). O componente arbóreo pode causar aumento, diminuição ou nenhum efeito sobre o componente forrageiro (PORFÍRIO-DA-SILVA, 2007).

Os valores de massa de forragem de capim braquiarão e capim quicuio da amazônia observadas neste estudo 
foram superiores àqueles relatados por Costa et al. (2001), em Rondônia. Considerando a quantidade de massa de forragem verde inferior a $0,75 \mathrm{t}$, como sendo limitante para a produção de bovinos (EUCLIDES; EUCLIDES FILHO, 1998), as pastagens dos SSPs estudados não apresentam limitações para as funções produtivas do gado.

\section{Proteína bruta (PB)}

A análise estatística não mostrou efeito significativo $(\mathrm{P} \leq 0,05)$ no teor de proteína bruta da folha (Tabela 4).

Tabela 4. Proteína bruta (\%) das folhas das pastagens em sistema silvipastoril, em Paragominas, Pará.

\begin{tabular}{lcccc}
\hline \multirow{2}{*}{ Pastagens } & \multicolumn{3}{c}{ Espécies florestais } & \multirow{2}{*}{$\begin{array}{c}\text { Média } \\
\text { geral }\end{array}$} \\
\cline { 2 - 4 } & Paricá & Tatajuba & Eucalipto & \\
\hline Braquiarão & 5,1 & 5,9 & 4,7 & $\mathbf{5 , 2 a}$ \\
Quicuio & 5,7 & 5,7 & 5,7 & $\mathbf{5 , 7 a}$ \\
Dictioneura & 6,2 & 5,8 & 6,5 & $\mathbf{6 , 2 a}$ \\
\hline Média geral & $\mathbf{5 , 7 a}$ & $\mathbf{5 , 8 a}$ & $\mathbf{5 , 6 a}$ & - \\
\hline
\end{tabular}

Médias gerais seguidas da mesma letra na linha e na coluna não diferem entre si $(\mathrm{P}>0,05)$ pelo teste de Tukey.

Os teores de PB observados neste estudo foram inferiores àqueles relatados por Oliveira et al. (2007) com o capim braquiarão em SSP.

O teor de proteína bruta das pastagens estudadas ficou abaixo do mínimo de $7 \%$, considerado como crítico para um bom desenvolvimento da flora ruminal de bovinos em pastejo (MINSON, 1990). Entretanto, os valores de massa de forragem, observados neste estudo, permitem aos animais selecionarem forragem de melhor qualidade.

\section{Capacidade de suporte}

Os valores de capacidade de suporte dos SSPs estudados estão de acordo com a performance em massa de forragem da pastagem. Assim, as maiores capacidades de suporte tenderam a ocorrer nos SSPs com capim braquiarão, e as menores nos SSPs com paricá (Tabela 5).

A capacidade de suporte de pastagens no subbosque depende do potencial forrageiro e do estágio de crescimento do componente arbóreo (KNOWLES, 1991). Assim, esses resultados confirmam a superioridade do capim braquiarão em qualquer combinação silvipastoril estudada e o efeito negativo do paricá, pelo seu maior desenvolvimento, na produção de forragem do subbosque silvipastoril.
Tabela 5. Capacidade de suporte $\left(\mathrm{UA}^{\mathrm{h}} \mathrm{ha}^{-1}\right)$ de sistemas silvipastoris, em Paragominas, Pará.

\begin{tabular}{lcccc}
\hline \multirow{2}{*}{ Pastagens } & \multicolumn{3}{c}{ Espécies florestais } & Média \\
\cline { 2 - 4 } & Paricá & Tatajuba & Eucalipto & geral \\
\hline Braquiarão & 0,49 & 0,55 & 0,59 & $\mathbf{0 , 5 4}$ \\
Quicuio & 0,27 & 0,45 & 0,45 & $\mathbf{0 , 3 9}$ \\
Dictioneura & 0,38 & 0,48 & 0,52 & $\mathbf{0 , 4 6}$ \\
\hline Média geral & $\mathbf{0 , 3 8}$ & $\mathbf{0 , 4 9}$ & $\mathbf{0 , 5 2}$ & - \\
\hline
\end{tabular}

$1 \mathrm{UA}=450 \mathrm{~kg}$ de peso vivo.

\section{Potencial das pastagens em sistemas silvipastoris}

Com a ausência de efeito das espécies na qualidade da pastagem (PB da folha), os únicos parâmetros de diferenciação do potencial das pastagens estudadas são a massa de forragem e, como consequência, a capacidade de suporte. Assim, no aspecto quantitativo, a pastagem de braquiarão suplantou as outras estudadas. Adicionalmente, esta pastagem possibilitou maior tempo de pastejo regular (42 meses) que as outras plantadas inicialmente - capim quicuio da amazônia (22 meses) e capim colonião (5 meses).

Nos sistemas pecuários da região, numa pastagem solteira bem formada (cobrindo mais de 95\% da área) e adequadamente manejada, considerando a pressão e a frequência de pastejo, a capacidade de suporte gira em torno de 1 UA por hectare. Assim, a maior capacidade de suporte obtida (na combinação eucalipto $\mathrm{x}$ braquiarão) alcançou apenas $60 \%$ do potencial. Do mesmo modo, o potencial florestal num SSP, no mínimo, será reduzido proporcionalmente à redução da densidade de árvores.

A presença das árvores na pastagem exige algumas mudanças no padrão usual de manejo de pastejo. Por exemplo, para evitar danos às árvores ainda jovens, altas pressões de pastejo, principalmente com animais adultos, mesmo que por pouco tempo, devem ser evitadas. Além do mais, é recomendado se manter pastagens convencionais (solteiras) para alimentar o rebanho em caso de necessidade (VEIGA et al., 2001).

\section{Perspectivas gerais dos sistemas silvipastoris}

À luz dos dados obtidos neste estudo, de modo geral, os componentes de SSP de melhor desempenho foram o paricá e o capim braquiarão. Por conseguinte, a combinação silvipastoril composta desses dois componentes tem grande chance de sucesso na região de estudo. 
Contudo, essas afirmações se baseiam apenas na produção biológica e na finalidade da exploração. $\mathrm{O}$ fator econômico poderá modificar completamente essa lógica, levando o usuário dessa tecnologia a priorizar o lucro e atender as demandas do mercado.

A adoção de SSP por parte dos produtores vai depender de fatores econômicos e sociais. Dentre as barreiras econômicas, operacionais e culturais para a adoção de SSP, destacam-se, respectivamente, os maiores investimentos iniciais para a implantação do SSP e ao tempo demandado para que as árvores cresçam o suficiente para gerar benefícios financeiros, o uso intenso de mão de obra e insumos, e a percepção por parte dos produtores das características e potencialidades agronômicas desses sistemas (DIAS-FILHO; FERREIRA, 2007).

\section{Conclusões}

Os componentes silvipastoris de melhor desempenho individual foram o paricá e o capim braquiarão;

Do ponto de vista da produção florestal, o sistema silvipastoril composto por paricá e braquiarão tem maior chance de sucesso;

Do ponto de vista da produção pecuária, o sistema mais apropriado é o composto do eucalipto e capim braquiarão.

\section{Referências}

ALMEIDA, E.; SABOGAL, C.; BRIENZA JÚNIOR, S. (1. Ed.). Recuperação de áreas alteradas na Amazônia brasileira: experiências locais, lições aprendidas e implicações para políticas públicas. Belém, PA: CIFOR, 2006. 202 p. il. p.

ARCO-VERDE, M.; SCHWENGBER, D. R. Avaliação silvicultural de espécies florestais no estado de Roraima. Revista Acadêmica Ciências Agrárias e Ambientais, Curitiba, v.1, n.3, p. 59-63, jul./set. 2003.

ASSOCIATION OF OFFICIAL ANALYTICAL CHEMISTS. Official Methods of Analysis of the AOAC. 11.ed. Washington DC, 1970. $1015 \mathrm{p}$.

BRIENZA JÚNIOR, S.; YARED, J.A.G. Agroforestry systems as an ecological approach in the Brazilian Amazon development. In: INTERNATIONAL CONFERENCE ON AGROFORESTRY: PRINCIPLES AND PRACTICES, 1991, Edinburgh - UK. Agroforestry: principles and practices. Edinburgh, 1991. p. 319-323.

CARVALHO, M. M.; FREITAS, V. P.; FRANCO, E. T.

Comportamento de gramíneas forrageiras tropicais em associação com árvores. In: CONGRESSO BRASILEIRO EM SISTEMAS

AGROFLORESTAIS, 2., 1998, Belém. No contexto da qualidade ambiental e competitividade: Resumos expandidos... Belém: Embrapa-CPATU, 1998. p. 195-197.
CASTRO, C. R.; CARVALHO, M. M.; GARCIA, R.; COUTO, L. Efeito do sombreamento artificial sobre o valor nutritivo de seis gramíneas forrageiras. In: CONGRESSO BRASILEIRO EM SISTEMAS AGROFLORESTAIS, 2., 1998, Belém. No contexto da qualidade ambiental e competitividade: Resumos expandidos... Belém: Embrapa-CPATU, 1998. p. 198-200.

COSTA, N. de L.; TOWNSEND, C. R.; MAGALHÃES, J. A.; PAULINO, V. T.; PEREIRA, R. G. de A. Utilização de sistemas silvipastoris na Amazônia Ocidental Brasileira. Revista Eletrônica de Veterinária REDVET, v. 7, n. 01, ene. 2006.

Disponível em $<$ http://www.veterinaria.org/revistas/redvet/ n010106/010608.pdf>. Acesso em: 25 set. 2006.

COSTA, N. de L.; TOWNSEND, C. R.; MAGALHÃES, J. A.; PEREIRA, R. G. de A. Avaliação agronômica de gramíneas forrageiras sob sombreamento de eucaliptos na Amazônia Ocidental. Amapá Ciência e Tecnologia, Macapá, v. 2, n. 2, p. 261-268, 2001

DIAS-FILHO, M. B.; FERREIRA, J. N. Barreiras à adoção de sistemas silvipastoris no Brasil. In: FERNANDES, E. N.; PACUILLO, D. S.; CATRO, C. R. T.; MULLER, M. D.; ARCURI, P. B.; CARNEIRO, J. C. (Ed.). Sistemas agrossilvipastoris na América do Sul: desafios e potencialidades. Juiz de Fora: Embrapa Gado de Leite, 2007. p. 327-340.

EUCLIDES, V. P. B.; EUCLIDES FILHO, K. Uso de animais na avaliação de forrageiras. Campo Grande, MS: EMBRAPACNPGC, 1998. 59 p. (EMBRAPA-CNPGC. Documentos, 74).

FERREIRA, L. M. M.; TONINI, H.; XAUD, H. A. M.; MOURÃO-JÚNIOR, M; ARCO-VERDE, M. F. Crescimento inicial de espécies madeiráveis em sistemas agroflorestais na região do Apiaú, Boa Vista: Embrapa Roraima, 2005. 4 p. (Embrapa Roraima. Comunicado Técnico, 1).

FRANKE, I. L. Sistemas silvipastoris, uma alternativa promissora para a pecuária no estado do Acre. Rio Branco, AC: Embrapa Acre, 1999. 3p. (Pesquisa em andamento, 155).

GARCIA, R.; COUTO, L. Sistemas silvipastoris: tecnologia emergente de sustentabilidae. In: SIMPÓSIO INTERNACIONAL SOBRE PRODUÇÃO ANIMAL EM PASTEJO, 1., 1997, Viçosa. Anais... Viçosa: UFV, 1997. p. 446-471.

KNOWLES, R. L. New Zealand experience with silvopastoral systems: a review. Forest Ecology and Management, n. 45, p. 167-251. 1991.

MANESCHY, R. Q.; SANTANA, A. C.; VEIGA, J. B. da;FILGUEIRAS, G. C. Análisis económico de sistema silvipastoriles con paricá (Schizolobium amazonicum Huber) em el nordeste de Pará, Brasil. Zootecnia Tropical, v. 26, n. 3, p. 403-405, 2008.

MARQUES, L. C. T. Comportamento inicial de paricá tatajuba e eucalipto, em plantios consorciados com milho e capimmarandu, em Paragominas, Pará. Vicosa: UFV, 1990. 92 p. Tese Mestrado.

MINSON, D. J. Forage in ruminant nutrition. London: Academic Press, 1990. 483p. 
MOCHIUTTI, S.; MEIRELLES, P. R. de L. Sistemas silvipastoris no Amapá: situação atual e perspectivas. In: CARVALHO, M. M.; ALVIM, M. J.; CARNEIRO, J. C. (Ed.). Sistemas agroflorestais pecuários: opções de sustentabilidade para áreas tropicais e subtropicais. Juiz de Fora: Embrapa Gado de Leite; Brasília: FAO, 2001. p. 77-99.

OLIVEIRA, T. K. de; MACEDO, R. L. G.; SANTOS, I. P. A. dos; HIGASHIKAWA, E. M.; VENTURIM, N. Produtividade de Brachiaria brizantha (Hochst. ex A. Rich) Stapf cv. Marandu sob diferentes arranjos estruturais de sistema agrossilvipastoril com eucalipto. Ciência Agrotecnica, Lavras, v. 31, n. 3, p. 748-757, maio/jun. 2007.

PORFÍRIO-DA-SILVA, V. Arborização de pastagens como prática de manejo ambiental e estratégia para o desenvolvimento sustentável no Paraná. In: CARVALHO, M. M.; ALVIM, M. J.; CARNEIRO, J. C. (Ed.). Sistemas agroflorestais pecuários: opção de sustentabilidade para áreas tropicais e subtropicais. Juiz de Fora: Embrapa Gado de Leite; Brasília: FAO, 2001. p. 235-255.

PORFÍRIO-DA-SILVA, V. Ecologia a manejo em sistema silvipastoril. In: FERNANDES, E. N.; PACUILLO, D. S.; CATRO, C. R. T.; MULLER, M. D.; ARCURI, P. B.; CARNEIRO, J. C. (Ed.). Sistemas agrossilvipastoris na América do Sul: desafios e potencialidades. Juiz de Fora: Embrapa Gado de Leite, 2007. p. 51-67.
RIBEIRO, G. D. Avaliação preliminar de sistemas agroflorestais no projeto Água Verde, ALBRÁS, Barcarena, PA. Belém, 1997. 110p. Dissertação (Mestrado em Ciências Florestais) - Faculdade de Ciências Agrárias do Pará, Belém.

VEIGA, J. B.; ALVES, C. P.; MARQUES, L. C. T.; VEIGA, D. F. Sistemas silvipastoris na Amazônia Oriental. In: CARVALHO, M. M.; ALVIM, M. J.; CARNEIRO, J. C. (Ed.). Sistemas agroforestais pecuários: opção de sustentabilidade para áreas tropicais e subtropicais. Juiz de Fora: Embrapa Gado de Leite; Brasília: FAO, 2001. p. 41-76.

VEIGA, J. B.; MARQUES, L. C. T. Desempenho de sistemas silvipastoris em Paragominas, Estado do Pará. In: CONGRESSO BRASILEIRO EM SISTEMAS AGROFLORESTAIS, 2, 1998. Belém. Sistemas agroflorestais no contexto da qualidade ambiental e competividade: resumos expandidos... Belém: Embrapa-CPATU, 1998. p.224-227. il.

VEIGA, J. B.; TOURRAND, J. F. Potencial e adoção de sistemas silvipastoris na Amazônia Oriental. In: CONGRESSO BRASILEIRO DE SISTEMAS AGROFLORESTAIS, 4., 2002, Ilhéus, BA. Anais. [S.1.]: CEPLAC, 2002. 1 CD-ROM. il.

Recebido em 15 de maio de 2009 e aprovado em 21 de dezembro de 2009 
